Article

\title{
Stereolithography 3D-Printed Catalytically Active Devices in Organic Synthesis
}

\author{
Sergio Rossi *(D), Alessandra Puglisi, Laura Maria Raimondi and Maurizio Benaglia *(i) \\ Dipartimento di Chimica, Università degli Studi di Milano, Via Golgi 19, 20133 Milano, Italy; \\ alessandra.puglisi@unimi.it (A.P.); lauramaria.raimondi@unimi.it (L.M.R.) \\ * Correspondence: sergio.rossi@unimi.it (S.R.); maurizio.benaglia@unimi.it (M.B.); Tel.: +39-02-5031-4166 (S.R.); \\ +39-02-5031-4171 (M.B.); Fax: +39-02-5031-4159 (S.R. \& M.B.)
}

Received: 12 December 2019; Accepted: 8 January 2020; Published: 12 January 2020

\begin{abstract}
This article describes the synthesis of stereolithography (SLA) 3D-printed catalyst-impregnated devices and their evaluation in the organocatalyzed Friedel-Crafts alkylation of $\mathrm{N}$-Me-indole with trans- $\beta$-nitrostyrene. Using a low-cost SLA 3D printer and freeware design software, different devices were designed and 3D-printed using a photopolymerizable resin containing a thiourea-based organocatalyst. The architectural control offered by the 3D-printing process allows a straightforward production of devices endowed with different shapes and surface areas, with high reproducibility. The 3D-printed organocatalytic materials promoted the formation of the desired product up to a $79 \%$ yield, although with longer reaction times compared to reactions under homogeneous conditions.
\end{abstract}

Keywords: heterogeneous catalysis; stereolithography; 3D printing; additive manufacturing; thiourea

\section{Introduction}

Three-dimensional (3D) printing, also known as additive manufacturing, refers to the process of producing 3D solid objects through the successive layering deposition of material. In the last few years, $3 \mathrm{D}$ printing has drawn attention in various fields due to its ability to create prototypical parts according to virtual concepts, and this technology has had very fast development in many scientific applications, such as in dentistry and odontology fields [1,2], medical implants [3], the aerospace and aircraft industries [4,5], jewelry making [6], clothes-manufacturing [7], food processing [8], and architecture [9].

Chemistry has also been drawn to 3D printing [10]; the technique represents an enabling tool in pharmaceutical and biological applications [11,12], as well as in organic synthesis [13], where sensors [14] and fluidic devices [15-19] were created. Three-dimensional printing applications range from the educational field, with the fabrication of molecular models [20] and cheap lab equipment [21], to the Active Pharmaceutical Ingredient (API) industry, where APIs such as Spritam are manufactured with a 3D-printing system [22].

Advantages of 3D-printing technology are related to its accessibility due to a thriving open-source community, to high customization freedom and cost-effectiveness (3D-printed objects cost less than those sold by supply companies), and to its sustainability in terms of employed materials and amount of generated waste.

Continuing our developments in the application of 3D-printing technology in organic synthesis $[13,19]$, we investigated the design and the creation of stereolithography (SLA) 3D-printed catalytically active devices to be used as catalysts in synthetic transformations. SLA technology is the first patented 3D-printing technology [23], and the process works by focusing an ultraviolet (UV) light onto a vat of photopolymer resin. UV light is used to draw a preprogrammed design onto the surface of the photopolymer. Because photopolymers are photosensitive under ultraviolet light, the resin is 
solidified and forms a single layer of the desired 3D object. This process is repeated for each layer upon completion of the desired object.

The possibility to create a 3D-printed device containing an embedded organocatalyst is very attractive, since the catalyst could be immobilized on solid support without the need for any chemical modification of the catalyst itself. The supported catalytic species could easily be removed upon a completed reaction and, possibly, be reused in further reactions. Advantages of this approach are similar to those of immobilized species, such as easily completed isolation and purification procedure [24].

Only very few examples of this approach are known so far. Sotelo, Gil, and coworkers developed a 3D-printed woodpile structure composed of a $5 \mathrm{wt} \%$ catalytic copper species immobilized onto $\mathrm{Al}_{2} \mathrm{O}_{3}$ support. Those devices showed good catalytic efficacy and good recyclability in different Ullmann reactions employed for the synthesis of imidazoles, benzimidazoles, and $N$-aryl amides [25]. In 2017, the same group reported that a 3D-printed woodpile that was made up of sintered $\mathrm{Al}_{2} \mathrm{O}_{3}$ could act as a Lewis acid catalyst in the synthesis of biologically active 1,4-dihydropyridines and 3,4-dihydropyrimidin-2(1H)-ones under solventfree conditions with microwave irradiation [26]. In another example, Hilton filed a patent application disclosing the realization of 3D-printing impregnated plastics for chemical reactions [27]. Magnetic stirring-bar hosts were created by a stereolithographic technique; a $p$-toluenesulfonic acid catalyst was embedded in the photopolymer resin, and the "catalytic stirrer" was used to promote a Mannich reaction in good yields.

In order to further expand the classes of embedded catalysts in 3D-printed devices, we investigated the incorporation of different organocatalysts into photocurable resins, which were subjected to a 3D-printing stereolithographic process for the creation of functionalized devices.

For this, we selected thiourea (4) as the catalyst of choice for our preliminary investigations. This organocatalyst is robust, highly versatile, and, among other attributes, able to promote the Friedel-Crafts alkylation of $N$-Me-indole (1) with trans- $\beta$-nitrostyrene (2) to afford the 3 -substituted indole derivative (3) in quantitative yields (Scheme 1) [28].

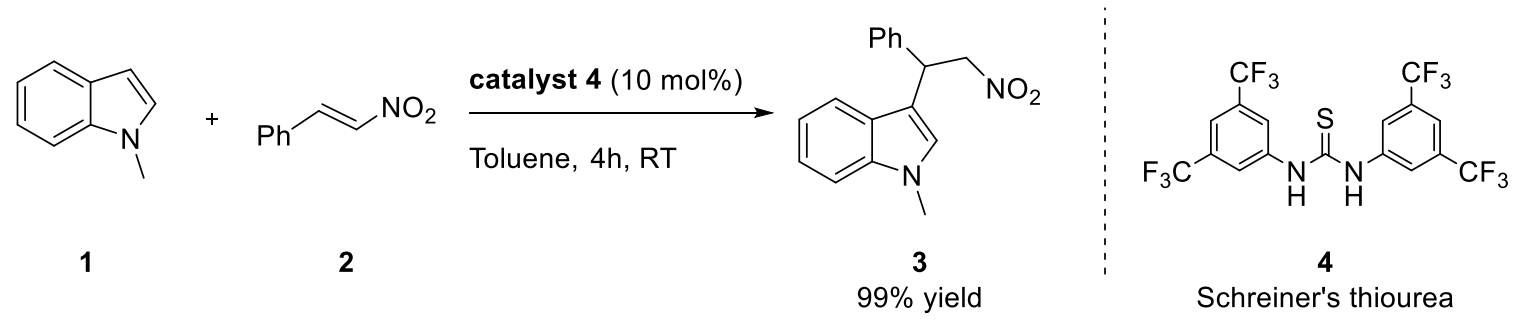

Scheme 1. Organocatalyzed Friedel-Crafts alkylation of $N$-Me-indole with trans- $\beta$-nitrostyrene.

Some issues need to be addressed in the development of the embedded catalyst in 3D-printed devices: (i) resin compatibility towards used solvent and reactants; (ii) 3D printability of resin with modified composition; (iii) catalyst leaching phenomena during the chemical transformation; and (iv) identification of the optimal device shape to be 3D-printed.

\section{Results and Discussion}

Commercially available "clear" photopolymerizable resin, compatible with Formlabs Form 2 3D printer, was selected as the resin of choice. This methacrylate-based resin is commercially available at low cost and it has a good chemical resistance to solvents, as certified by the manufacturer [29]. Since no compatibility information has been reported with toluene, we replicated the swelling test of the manufacturer using this solvent (see Supporting Information (SI) for further details). Weight gain over $24 \mathrm{~h}$ for a printed and postcured (see SI) $1 \times 1 \times 1 \mathrm{~cm}$ cube immersed in toluene was less than $1 \%$, and, after 3 months, no appreciable deformations were observed. This solvent was chosen as the preferred reaction medium for the addition of indoles to trans- $\beta$-nitrostyrene. Additional tests were performed using a $0.15 \mathrm{M}$ toluene solution of $N-\mathrm{Me}-$ indole, a $0.1 \mathrm{M}$ toluene solution of trans- $\beta$-nitrostyrene, and a 
$0.1 \mathrm{M}$ toluene solution of compound 3; in each case, no deformation was observed after one week. Having established the compatibility of "clear" resin with these mixtures, we focused our attention on the capability of resins loaded with a different weight \% amount of thiourea 4 to undergo the photopolymerization process. Mixtures obtained by combination of clear resin and with the desired amount of catalyst 4 were subjected to ultrasound irradiation for $30 \mathrm{~min}$, followed by orbital shake mixing ( $30 \mathrm{~min}, 400 \mathrm{rpm}$ ) in order to guarantee the homogeneity of the viscous mixture. Subsequently, a thin layer of resin was subjected to polymerization by irradiation with a UV lamp $(365 \mathrm{~nm})$ for $2 \mathrm{~h}$. Results are reported in Table 1.

Table 1. Investigation on ultraviolet (UV) polymerization of resin samples containing thiourea catalyst.

\begin{tabular}{cccc}
\hline Sample & Thiourea (weight \%) & $\begin{array}{c}\text { Catalyst Loading } \\
(\mathbf{m m o l} / \mathbf{g})\end{array}$ & $\begin{array}{c}\text { UV Polymerization } \\
\text { Occurred }\end{array}$ \\
\hline Resin 1 & 1 & 0.019 & Yes \\
Resin 2 & 5 & 0.111 & Yes \\
Resin 3 & 10 & 0.222 & Yes \\
Resin 4 & 15 & 0.299 & Yes \\
Resin 5 & 20 & 0.389 & Yes \\
\hline
\end{tabular}

According to this survey, in each of the cases studied, the polymerization process occurred positively. This thin solid cross-linked resin layer was then washed with isopropanol, sonicated for $15 \mathrm{~min}$, air dried, and finally chipped into small flakes. These thiourea-embedded slivers were then used to catalyse the addition of $N$-Me-indole to trans- $\beta$-nitrostyrene. In a typical experiment, $1 \mathrm{~mol} / \mathrm{equiv}$ of trans- $\beta$-nitrostyrene was reacted with $1.5 \mathrm{~mol} /$ equiv of $\mathrm{N}$-Me-indole in a $0.1 \mathrm{M}$ toluene solution and stirred by an orbital shaker (400 rpm) for $24 \mathrm{~h}$ at room temperature. Yields were determined by ${ }^{1} \mathrm{H}$ NMR using 1,3,5-trimethoxybenzene as internal standard and are reported in Table 2 [30].

Table 2. Friedel-Crafts alkylation of $N$-Me-indole with trans- $\beta$-nitrostyrene promoted by embedded thiourea UV-polymerized resin.

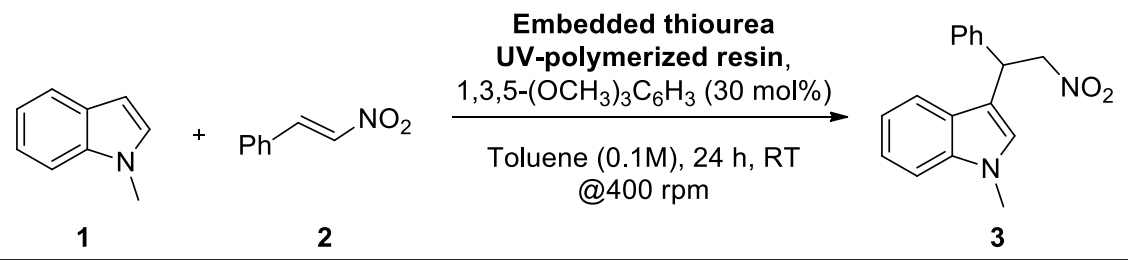

\begin{tabular}{cccc}
\hline Entry & $\begin{array}{c}\text { Thiourea Loading (wt } \\
\mathbf{\%})\end{array}$ & $\begin{array}{c}\text { Embedded-Catalyst/Substrate } \\
\text { Ratio (mol/mol) }\end{array}$ & Yield $^{\mathbf{1}}$ \\
\hline 1 & - & - & - \\
2 & 1 & 0.1 & - \\
3 & 5 & 0.1 & - \\
4 & 10 & 0.1 & - \\
5 & 10 & 0.3 & - \\
6 & 10 & 0.5 & 23 \\
7 & 10 & 1 & - \\
8 & 15 & 0.3 & 7 \\
9 & 15 & 0.5 & 7 \\
10 & 15 & 1 & 14 \\
11 & 20 & 0.1 & 25 \\
12 & 20 & 0.2 & 49 \\
13 & 20 & 0.5 & 53 \\
14 & 20 & 1 & 2 \\
\hline
\end{tabular}

${ }^{1}$ Calculated by ${ }^{1} \mathrm{H}$ NMR using 1,3,5-trimethoxybenzene as internal standard. 
As shown, no product formation occurred when polymerized resin flakes without embedded thiourea 4 were used (Entry 1). Reactions performed in the presence of thiourea-embedded slivers with low catalyst loading or with low embedded-catalyst/substrate ratios gave no product or very poor results (Entries 2-9). However, when a 15 weight \% thiourea-embedded resin was used in an equimolar ratio with the substrate, product 4 was formed in a $60 \%$ yield (Entry 10). Positive results were also obtained using resins with higher catalyst loading (Entries 14-15).

In order to confirm that the Friedel-Crafts alkylation of N-Me-indole with trans- $\beta$-nitrostyrene was catalyzed by heterogeneous thiourea-embedded flakes and not promoted by homogeneous catalyst 4 released from the resin in solution, we evaluated the leaching of the catalyst using different procedures. At first, 10 weight \% thiourea slivers were refluxed with chloroform in a Soxhlet apparatus for $24 \mathrm{~h}$. Since "clear" resin is not stable under chlorinated solvents (see Supporting Information), further sliver fragmentation was observed. After solvent evaporation, the resulting solid material was analyzed by NMR; only signals belonging to the polymer material were detected, with no evidence of catalyst signals in the crude form.

In an additional test, the crude reaction mixtures of Entries 7 and 11 in Table 2 were analyzed by ${ }^{19} \mathrm{~F}$ NMR in order to verify the absence/presence of a thiourea 4 fluorine signal. Only very minor traces of the catalyst were detected in the solution. In order to quantitatively analyze the catalyst leaching of the slivers loaded with different amounts of catalyst $4,{ }^{19} \mathrm{~F}$ NMR analysis was performed using a $0.017 \mathrm{M}$ solution of hexafluorobenzene in toluene as ${ }^{19} \mathrm{~F}$ NMR internal standard. Results are reported in Figure 1.

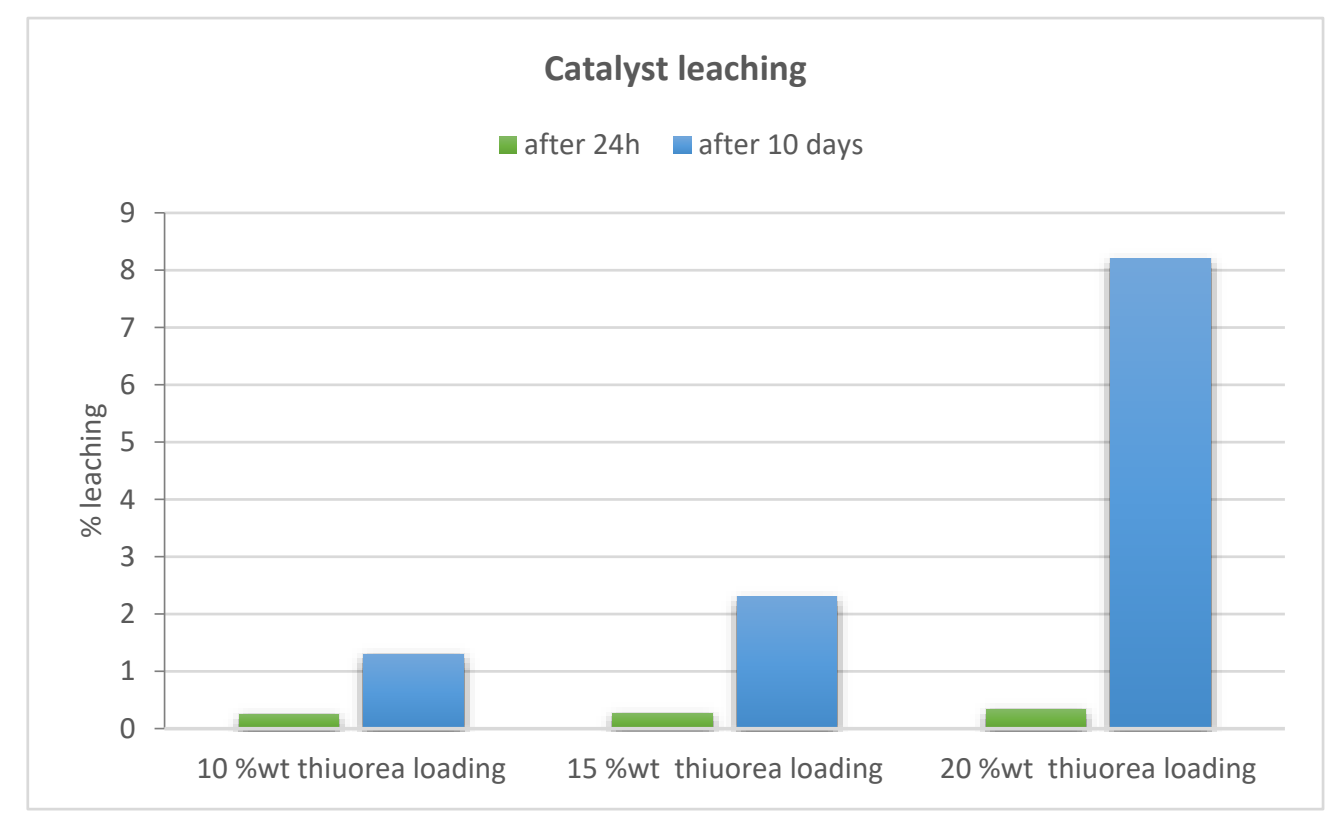

Figure 1. Wt \% catalyst leaching calculated on entire catalyst amount dissolved in resin.

As shown, $10 \mathrm{wt} \%$ thiourea-embedded material showed a catalyst leaching of $0.25 \mathrm{wt} \%$ after $24 \mathrm{~h}$, and $1.3 \mathrm{wt} \%$ after 10 days of continuous shaking at $400 \mathrm{rpm}$. In addition, 15 and $20 \mathrm{wt} \%$ thiourea-embedded flakes showed comparable negligible leaching after $24 \mathrm{~h}(0.27 \%$ and $0.33 \%$, respectively); after 10 days, the first showed catalyst leaching of $2.5 \%$, while $8.2 \mathrm{wt} \%$ leaching was detected for the second.

Therefore, we selected $15 \mathrm{wt} \%$ resin as a good compromise between efficiency and (re)usability. However, the observed catalyst leaching $(0.27 \mathrm{wt} \%)$ was not sufficient to promote Friedel-Crafts alkylation. Indeed, after $24 \mathrm{~h}$ reaction between $\mathrm{N}-\mathrm{Me}$-indole and trans- $\beta$-nitrostyrene $(60 \%$ yield, Entry 7, Table 2), thiourea-embedded slivers were removed, and the reaction was shaken for $24 \mathrm{~h}$ more. 
After this period, no yield increase was observed, confirming that the small amount of catalyst leached during the reaction was not able to promote the reaction by itself.

On the basis of these positive preliminary results using thiourea-embedded flakes of methacrylate-based resin as a catalyst in organocatalytic Friedel-Crafts alkylation, we focused our attention on the creation of devices with a well-defined shape that could be manufactured using an SLA 3D-printing process. Considering that the higher performance of catalysts could be related to increased exposed surface areas (as for a typical heterogeneous process), we designed four different devices characterized by the presence of many grooves. Autodesk $123 \mathrm{~d}$ design freeware CAD software [31] was used to design and generate the corresponding Surface Tessellation Language (.stl) files. The rendering of these devices is reported in Figure 2.

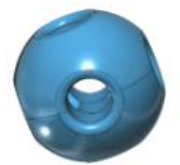

Device 1 Sphere

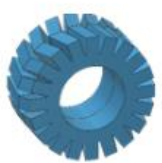

Device 2

Gear wheel

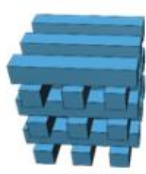

Device 3

Cubic woodpile

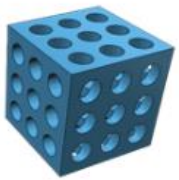

Device 4

Holed cube

Figure 2. Three-dimensionally printed devices.

Device 1 consisted of a $6 \mathrm{~mm}$ diameter sphere with two circular channels (diameter $=1 \mathrm{~mm}$ ) and was characterized by $0.07 \mathrm{~cm}^{3}$ volume and $1.57 \mathrm{~cm}^{2}$ surface area. Device 2 was a "gear wheel" of $6 \mathrm{~mm}$ diameter and $3 \mathrm{~mm}$ height $\left(0.05 \mathrm{~cm}^{3}\right.$ volume, $2.06 \mathrm{~cm}^{2}$ surface area); Device 3 was a cubic woodpile structure $\left(6 \times 6 \times 6 \mathrm{~mm}, 0.11 \mathrm{~cm}^{3}\right.$ volume, and $3.78 \mathrm{~cm}^{2}$ surface area); and Device 4 was a cube with nine channels for each face $\left(6 \times 6 \times 6 \mathrm{~mm}, 0.10 \mathrm{~cm}^{3}, 4.36 \mathrm{~cm}^{2}\right.$ surface area).

Then, $150 \mathrm{~mL}$ of $10 \mathrm{wt} \%$ and $150 \mathrm{~mL}$ of $15 \mathrm{wt} \%$ thiourea (4)-embedded resin were prepared (with 0.300 and $0.199 \mathrm{mmol} / \mathrm{g}$ catalyst loading, respectively) and loaded into a Formlabs Form 2 stereolithography (SLA) 3D printer. The 3D-printing process was performed with $50 \mu \mathrm{m}$ layer thickness, and supports were added in order to facilitate the process. Multiple copies of the devices were simultaneously printed on the same build plate to provide a good number of catalytically active devices to be employed in Friedel-Crafts alkylation (Figure 3).
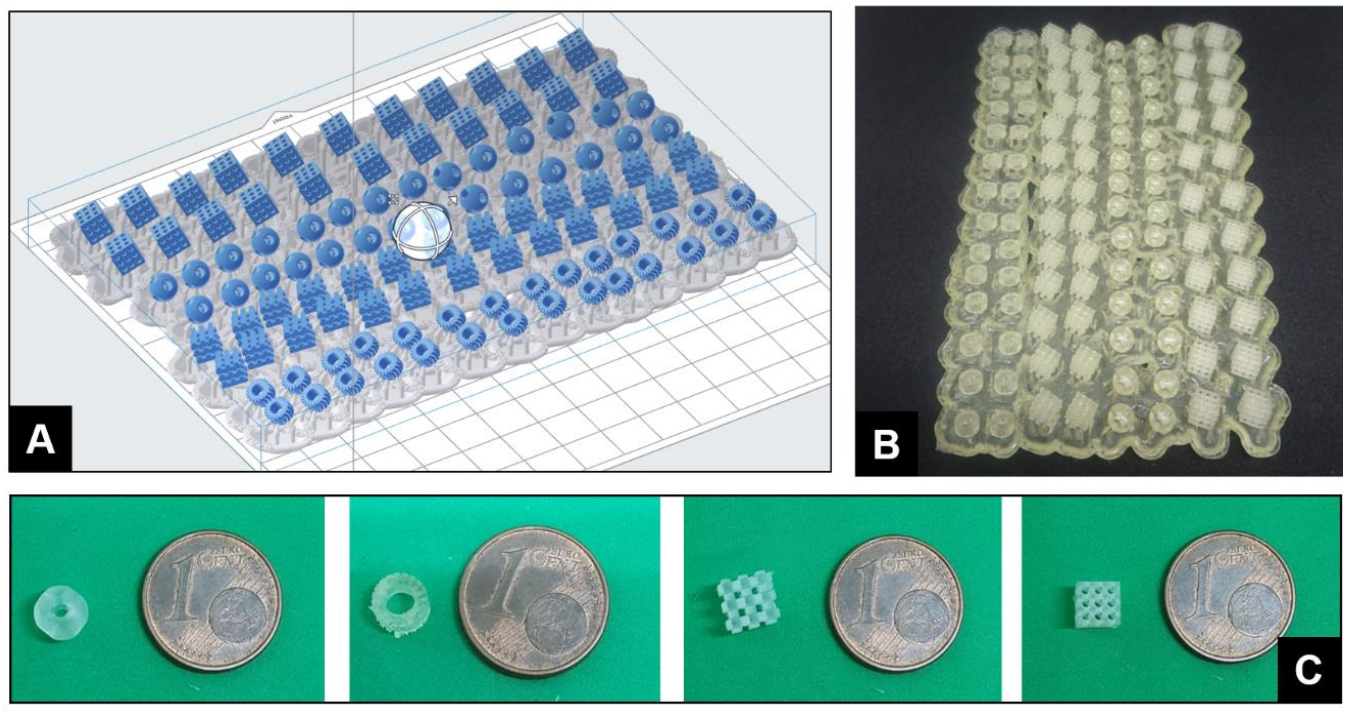

Figure 3. (A) Devices (blue) arranged on printer plate with software-generated supports (grey). (B) Devices obtained after 3D-printing process. (C) Devices 1-4 after support removal compared with $€ 0.01$ coin. 
Freshly printed objects need to be carefully cleaned before use to remove any residue of unpolymerized material. For this purpose, crude 3D-printed devices were sonicated in an $\mathrm{PrOH}$ bath for $20 \mathrm{~min}$, and the same operation was repeated twice with toluene until lost weight was lower than $1 \%$. After this washing process, the solvent was removed, and devices were air-dried prior to postcuring for 20 min under a UV lamp. Their efficiency as organocatalysts was then investigated in

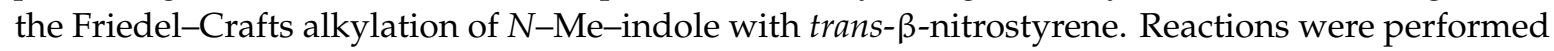
with different catalyst/substrate ratios $(\mathrm{mol} / \mathrm{mol}$ ) considering the required catalyst amount as the global amount of catalyst present into the entire device (the catalyst that is really accessible and interacts with the reactants is much less). Results are reported in Table 3.

Table 3. Friedel-Crafts alkylation promoted by stereolithography (SLA) 3D-printed devices.

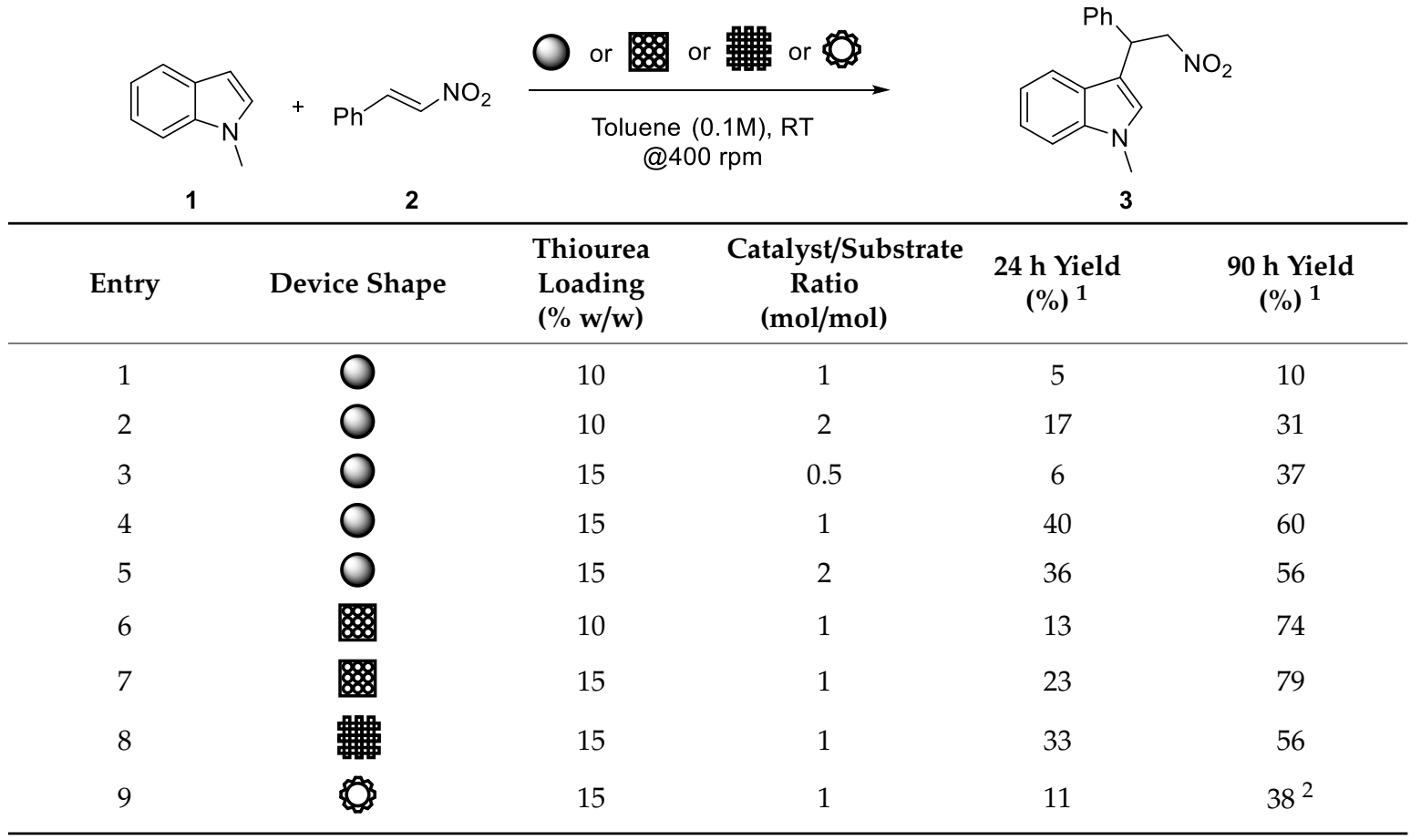

${ }^{1}$ Calculated by $1 \mathrm{H}$ NMR using 1,3,5-trimethoxybenzene as internal standard. ${ }^{2}$ Reaction time, $48 \mathrm{~h}$.

After completing the reactions, the catalytic devices were easily removed from the reaction mixture. All 3D-printed thiourea-embedded devices could promote the synthesis of compound 3, but longer reaction times were required. From a general point of view, devices realized with $10 \mathrm{wt} \%$ thiourea-embedded resin were characterized by less chemical efficiency in promoting the reaction compared to the same device realized at $15 \mathrm{wt} \%$ thiourea-embedded resin. However, spherical devices led to the formation of the desired compound in $60 \%$ yield when a 1:1 catalyst/substrate ratio was employed (Table 3, Entry 4). Comparable results were also obtained using holed-cube Device 4, which presented the highest exposed surface, while other device shapes seemed to be less effective in promoting the Friedel-Crafts alkylation of $N$-Me-indole with trans- $\beta$-nitrostyrene.

Preliminary recycling studies were also carried out using the described general procedures (1:1 catalyst/substrate ratio). The 3D-printed $15 \mathrm{wt} \%$ thiourea-embedded devices were used; although devices changed in color from yellow to pale orange, the reused devices were effective for a second run without significant loss of yield, but showed clear drop in efficiency in the third run (first run, $40 \%$; second run, $37 \%$; third run, $11 \%$ ). 


\section{Materials and Methods}

Reactions were monitored by analytical thin-layer chromatography (TLC, Merck KGaA, Darmstadt, Germany) using silica gel $60 \mathrm{~F}_{254}$-precoated glass plates $(0.25 \mathrm{~mm}$ thickness) and visualized using UV light. Flash chromatography was carried out on silica gel (230-400 mesh). Proton NMR spectra were recorded on spectrometers operating at $300 \mathrm{MHz}$ (Bruker Avance 300, Bruker, Billerica, MA, USA); proton chemical shifts were reported in $\mathrm{ppm}(\delta)$ with the solvent reference relative to tetramethylsilane (TMS) employed as the internal standard $\left(\mathrm{CDCl}_{3} \delta=7.26 \mathrm{ppm}\right) .{ }^{19} \mathrm{~F}$ NMR spectra were recorded on $300 \mathrm{MHz}$ spectrometers (Bruker Avance 300) operating at $282.1 \mathrm{MHz}$; fluorine chemical shifts were reported in ppm $(\delta)$ relative to $\mathrm{CF}_{3} \mathrm{Cl}$ with the respective solvent resonance as the internal standard $\left(\mathrm{CDCl}_{3}, \delta=77.0 \mathrm{ppm}\right)$. Three-dimensionally printed devices were created using a Formlabs Form $23 \mathrm{D}$ printer (Formlabs Inc., Somerville, MA, USA). Microwave reactions were performed using a Discovery-SP CEM microwave (CEM Corporation, Matthews, NC, USA) and photopolymerization was pursued using a Shengtuo Kangtuo SK-818 UV lamp. Dry solvents were purchased and stored under nitrogen over molecular sieves (bottles with crown caps, Merck KGaA, Darmstadt, Germany). All chemicals were purchased from commercial suppliers and used without further purification unless otherwise specified. Clear V4 resin was purchased from https://formlabs.com, and used as received.

\section{Conclusions}

In conclusion, in this work, 3D-printed thiourea-embedded devices were designed, prepared, and used in an organic transformation. Stereolithography 3D-printed catalytically active devices differing in shape and accessible surface were designed. Three-dimensionally printed organocatalytic materials were employed in the Friedel-Crafts alkylation of $N-\mathrm{Me}$-indole with trans- $\beta$-nitrostyrene, leading to the formation of the desired product up to a $79 \%$ yield, although longer reaction times were required compared to the reaction under homogeneous conditions. The architectural control offered by the 3D-printing process allowed the straightforward production of devices endowed with different shapes and surface areas, with high reproducibility. More studies are needed related to the characteristics and the properties of the monomer to be polymerized to increase catalyst accessibility, and improve catalytic efficiency and the reaction rate. Nevertheless, in the future, the same 3D-printing approach might be used to fabricate catalytically active objects that are able to efficiently promote other organic reactions, including stereoselective transformations catalyzed by chiral catalysts.

Supplementary Materials: The following are available online at http://www.mdpi.com/2073-4344/10/1/109/s1: details of the procedure and NMR traces of products reported in Supporting Information.

Author Contributions: Methodology and experimental work, S.R.; conceptualization and supervision, M.B.; experiment work, A.P.; data analysis, L.M.R. All authors have read and agreed to the published version of the manuscript.

Funding: This research was funded by the Università degli Studi di Milano, PSR 2018 granted to S. Rossi.

Conflicts of Interest: The authors declare no conflict of interest.

\section{References and Note}

1. Chaudhary, R.; Doggalli, N.; Chandrakant, H.V.; Patil, K. Current and evolving applications of three-dimensional printing in forensic odontology: A review. Int. J. Forensic Odontol. 2018, 3, 59-65. [CrossRef]

2. Dawood, A.; Marti Marti, B.; Sauret-Jackson, V.; Darwood, A. 3D printing in dentistry. Br. Dent. J. 2015, 219, 521-529. [CrossRef]

3. Yan, Q.; Dong, H.; Su, J.; Han, J.; Song, B.; Wei, Q.; Shi, Y. A Review of 3D Printing Technology for Medical Applications. Engineering 2018, 4, 729-742. [CrossRef]

4. Froes, F.; Boye, R. (Eds.) Additive Manufacturing for the Aerospace Industry, 1st ed.; Elsevier: Amsterdam, The Netherlands, 2019. 
5. Joshi, S.C.; Sheikh, A.A. 3D printing in aerospace and its long-term sustainability. Virtual Phys. Prototyp. 2015, 10, 175-185. [CrossRef]

6. Yap, Y.L.; Yeong, W.Y. Additive manufacture of fashion and jewellery products: A mini review. Virtual Phys. Prototyp. 2014, 9, 195-201. [CrossRef]

7. Kim, S.; Seong, H.; Her, Y.; Chun, J. A study of the development and improvement of fashion products using a FDM type 3D printer. Fash. Text. 2019, 6, 9. [CrossRef]

8. Guo, C.; Zhang, M.; Bhandari, B. Model Building and Slicing in Food 3D Printing Processes: A Review. Compr. Rev. Food Sci. F 2019, 18, 1052-1069. [CrossRef]

9. Yin, H.; Qu, M.; Zhang, H.; Lim, Y. 3D Printing and Buildings: A Technology Review and Future Outlook. Technol. Archit. Des. 2018, 2, 94-111. [CrossRef]

10. Hartings, M.R.; Ahmed, Z. Chemistry from 3D printed objects. Nat. Rev. Chem. 2019, 3, 305-314. [CrossRef]

11. Ho, C.M.; Ng, S.H.; Li, K.H.; Yoon, Y.J. 3D printed microfluidics for biological applications. Lab Chip 2015, 15, 3627-3637. [CrossRef]

12. Capel, A.J.; Rimington, R.P.; Lewis, M.P.; Christie, S.D.R. 3D printing for chemical, pharmaceutical and biological applications. Nat. Rev. Chem. 2018, 2, 422-436. [CrossRef]

13. Rossi, S.; Puglisi, A.; Benaglia, M. Additive Manufacturing Technologies: 3D Printing in Organic Synthesis. ChemCatChem 2018, 10, 1512-1525. [CrossRef]

14. Pohanka, M. Three-Dimensional Printing in Analytical Chemistry: Principles and Applications. Anal. Lett. 2016, 49, 2865-2882. [CrossRef]

15. Waldbaur, A.; Rapp, H.; Lange, K.; Rapp, B.E. Let there be chip-towards rapid prototyping of microfluidic devices: One-step manufacturing processes. Anal. Methods 2011, 3, 2681-2716. [CrossRef]

16. Capel, A.J.; Edmondson, S.; Christie, S.D.; Goodridge, R.D.; Bibb, R.J.; Thurstans, M. Design and additive manufacture for flow chemistry. Lab Chip 2013, 13, 4583-4590. [CrossRef] [PubMed]

17. He, Y.; Wu, Y.; Fu, J.-Z.; Gao, Q.; Qiu, J.-J. Developments of 3D Printing Microfluidics and Applications in Chemistry and Biology: A Review. Electroanalysis 2016, 28, 1658-1678. [CrossRef]

18. Monaghan, T.; Harding, M.J.; Harris, R.A.; Friel, R.J.; Christie, S.D. Customisable 3D printed microfluidics for integrated analysis and optimisation. Lab Chip 2016, 16, 3362-3373. [CrossRef]

19. Rossi, S.; Porta, R.; Brenna, D.; Puglisi, A.; Benaglia, M. Stereoselective Catalytic Synthesis of Active Pharmaceutical Ingredients in Homemade 3D-Printed Mesoreactors. Angew. Chem. Int. Ed. 2017, 56, 4290-4294. [CrossRef]

20. Rossi, S.; Benaglia, M.; Brenna, D.; Porta, R.; Orlandi, M. Three Dimensional (3D) Printing: A Straightforward, User-Friendly Protocol To Convert Virtual Chemical Models to Real-Life Objects. J. Chem. Educ. 2015, 92, 1398-1401. [CrossRef]

21. Rossi, S.; Dozzi, M.V.; Puglisi, A.; Pagani, M. 3D-printed, home-made, UV-LED photoreactor as a simple and economic tool to perform photochemical reactions in high school laboratories. Chem. Teach. Int. 2019. [CrossRef]

22. Yoo, J.; Bradbury, T.J.; Bebb, T.J.; Iskra, J.; Surprenant, H.L.; West, T.G. Three-Dimensional Printing System and Equipment Assembly. US Patent 9,908,293, 6 March 2014.

23. Melchels, F.P.; Feijen, J.; Grijpma, D.W. A review on stereolithography and its applications in biomedical engineering. Biomaterials 2010, 31, 6121-6130. [CrossRef] [PubMed]

24. Benaglia, M.; Puglisi, A.; Cozzi, F. Polymer-supported organic catalysts. Chem. Rev. 2003, 103, 3401-3429. [CrossRef]

25. Tubio, C.R.; Azuaje, J.; Escalante, L.; Coelho, A.; Guitian, F.; Sotelo, E.; Gil, A. 3D printing of a heterogeneous copper-based catalyst. J. Catal. 2016, 334, 110-115. [CrossRef]

26. Azuaje, J.; Tubio, C.R.; Escalante, L.; Gomez, M.; Guitian, F.; Coelho, A.; Caamano, O.; Gil, A.; Sotelo, E. An efficient and recyclable 3D printed alpha-Al2O3 catalyst for the multicomponent assembly of bioactive heterocycles. Appl. Catal. A Gen. 2017, 530, 203-210. [CrossRef]

27. Hilton, S.; Penny, M.; Dos Santos, B.S.; Patel, B. Three-Dimensional Printing of Impregnated Plastic for Chemical Reactions. Patent application WO2017158336A1, 21 September 2017.

28. Ricci, A.; Herrera, R.P.; Dessole, G. H-Bonding Organocatalysed Friedel-Crafts Alkylation of Aromatic and Heteroaromatic Systems with Nitroolefins. Synlett 2004, 13, 2374-2378.

29. These Informations are Described in the Safety Data Sheet. Available online: https://formlabs-media.formlabs. com/datasheets/Clear_Resin_Technical.pdf (accessed on 1 September 2019). 
30. See the Supporting Information for further details.

31. 123d Design, Version 2.2.14. The Software Is Not More Accessible from Autodesk, but It Can Be Downloaded from Other Sources. Available online: https://www.download-3d.com (accessed on 1 September 2019).

(C) 2020 by the authors. Licensee MDPI, Basel, Switzerland. This article is an open access article distributed under the terms and conditions of the Creative Commons Attribution (CC BY) license (http://creativecommons.org/licenses/by/4.0/). 